\title{
Phantom simulation of liver metastasis on a positron emission tomography with computed tomography scan after neoadjuvant chemoradiotherapy for distal esophageal cancer: a case report
}

\author{
Sen-Ei Shai ${ }^{1,2,4}$, Yuan-Hong Lin ${ }^{1}$, Yi-Ling Lai ${ }^{1}$, Hsiao-Wen Tang ${ }^{1}$, Yao-Wen Hsieh ${ }^{3}$ and Shih-Chieh Hung ${ }^{2,5,6^{*}}$
}

\begin{abstract}
Background: Neoadjuvant chemoradiotherapy is currently the gold standard treatment for esophageal cancer prior to surgery. This radiation therapy will sometimes lead to liver damage parallel to esophageal lesions, which mimics liver metastasis visualized by ${ }^{18} \mathrm{~F}$-fluorodeoxyglucose positron emission tomography with computed tomography. In this report, we publish virtual radiation-induced liver damage images obtained during surgery, along with the coherent pathology, in order to confirm the false-positive result through an optimally decisive radiological examination.

Case presentation: We report a case of a Asian male patient with distal esophageal cancer who had undergone neoadjuvant chemoradiotherapy (5000 cGy). Subsequently, a new lesion was discovered during a positron emission tomography with computed tomography scan 6 weeks later, near the left caudate lobe of the liver during tumor restaging. To exclude the possibility of liver metastasis, serial imaging was conducted, which included liver sonography, computed tomography, and magnetic resonance imaging for a more intimate probe. The patient's condition was verified as being liver inflammation change, as seen by the liver magnetic resonance imaging presentation.

Thoracoscopic esophagectomy was performed with cervical esophagogastrostomy via the retrosternal route, along with a feeding jejunostomy. The procedure was performed smoothly, with an intraoperative liver biopsy also being conducted 2 weeks later, after positron emission tomography with computed tomography restaging. The pathology report revealed esophageal cancer in the form of poorly differentiated squamous cell carcinoma, pT3N1M0. The liver biopsy revealed obvious inflammation change after radiation therapy, which elucidated sinusoidal congestion with the attenuated hepatic cords and filled with erythrocytes. There was no evidence of liver metastasis. The patient recovered uneventfully and was discharged with his oral intake performing smoothly, and a stable condition was observed during 12 months of outpatient department follow-up.

(Continued on next page)
\end{abstract}

\footnotetext{
* Correspondence: hung3340@gmail.com

${ }^{2}$ Institute of Clinical Medicine, National Yang-Ming University, Taipei, Taiwan

5 Institute of New Drug Development, China Medical University, Taichung

Joint PI, IBMS, Academia Sinica 7F, No. 6, Xueshi Road, North District,

Taichung City 404, Taiwan

Full list of author information is available at the end of the article
}

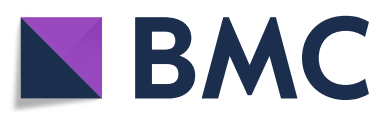

( ) The Author(s). 2020 Open Access This article is licensed under a Creative Commons Attribution 4.0 International License, which permits use, sharing, adaptation, distribution and reproduction in any medium or format, as long as you give appropriate credit to the original author(s) and the source, provide a link to the Creative Commons licence, and indicate if changes were made. The images or other third party material in this article are included in the article's Creative Commons licence, unless indicated otherwise in a credit line to the material. If material is not included in the article's Creative Commons licence and your intended use is not permitted by statutory regulation or exceeds the permitted use, you will need to obtain permission directly from the copyright holder. To view a copy of this licence, visit http://creativecommons.org/licenses/by/4.0/. The Creative Commons Public Domain Dedication waiver (http://creativecommons.org/publicdomain/zero/1.0/) applies to the data made available in this article, unless otherwise stated in a credit line to the data. 


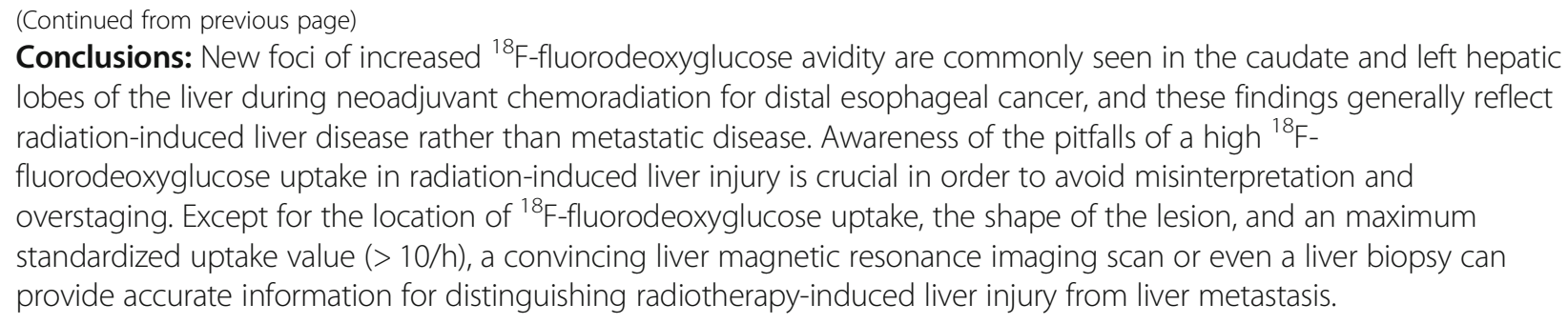

Keywords: Esophageal cancer, Radiation therapy, PET-CT scan, Liver metastasis

\section{Introduction}

Esophageal cancer is currently the eighth most common cancer worldwide. It is most prevalent in countries in eastern and southern Africa and eastern Asia. Threefourths of affected patients are male. Patients diagnosed with esophageal cancer have a very poor survival rate [1]. There is evidence that neoadjuvant chemoradiotherapy (CRT) will shrink tumor size, which increases the success rate of surgery. Additionally, it can improve the average 3-year survival rate, with the radiation reducing locoregional cancer recurrence [2]. Positron emission tomography with computed tomography (PET-CT) scans are currently performed as the gold standard approach for tumor staging of esophageal cancer worldwide $[3,4]$. The scans can be helpful in identifying the subset of patients who are responders to preoperative therapy while also detecting distant metastases, thereby excluding those patients who will not benefit from an esophagectomy [5]. Radiation therapy (RT) of distal esophageal cancer may include the adjacent liver parenchyma, which can appear on a PET-CT scan as an area of increased ${ }^{18} \mathrm{~F}$-fluorodeoxyglucose (FDG) uptake within the liver parenchyma that mimics metastatic disease [5]. Approximately $3-10 \%$ of patients are detected with new lesion uptake after the procedure, which may be attributed to interval metastasis $[4,6]$.

Use of PET-CT for restaging may encounter a dilemma in distinguishing radiation-induced hepatitis from the tumor with liver metastasis, which in turn may accentuate the false-positive rate of PET-CT with overstaging $[7,8]$. Accordingly, in this report, we describe a case with complete images from both preand post-neoadjuvant CRT, as well as a photograph of a damaged liver taken during surgery, along with a pathologic image. We also review the relevant literature regarding optimal detection to assist in excluding PET-CT false-positive misinterpretation after neoadjuvant chemoradiation.

\section{Case presentation}

A 66-year-old Asian man who had hypertension for which he had been receiving medication for 20 years presented to our hospital. He had been a heavy smoker and drinker for more than 30 years. He had experienced progressive swallowing difficulty for 3 months and a body weight loss of $5 \mathrm{~kg}$ in 1 month. Endoscopy disclosed that a huge tumor was occupying the esophagus $30 \mathrm{~cm}$ from the incisor to the esophagogastric junction, with a biopsy determining poorly differentiated squamous cell carcinoma. A whole-body PET-CT scan with ${ }^{18}$ F-FDG revealed a distinct FDG uptake in the lower esophagus (Fig. 1), and clinical stage cT3N1M0 was subsequently categorized. A chemoport was inserted, and a percutaneous endoscopic gastrostomy was performed prior to neoadjuvant CRT. The patient underwent a two-cycle chemotherapy regimen with cisplatin and 5fluorouracil, in combination with RT in 25 fractions at 5000 cGy, with no obvious side effects being noted. Following the feasibility of definitive surgery for esophageal resection and reconstruction, a PET-CT scan was performed again 6 weeks later upon completion of CRT in order to evaluate the effects of the neoadjuvant CRT (Fig. 2). It was at this time when a new FDG-avid lesion at the caudate lobe was discovered, and a formal report was written to address the liver metastasis (Fig. 3).

The tumor markers, including $\alpha$-fetoprotein (5.74 ng/ $\mathrm{ml})$, carcinoembryonic antigen $(3.27 \mathrm{ng} / \mathrm{ml})$, and squamous cell carcinoma-related antigen $(0.3 \mathrm{ng} / \mathrm{ml})$, disclosed nothing remarkable. A further imaging survey was performed to clarify the new lesion. Liver sonography (Fig. 4a) showed focally mild prominence in S1 of the liver with a slightly hypoechoic appearance, and CT of the liver revealed focally less enhancement in S1 of the liver (Fig. 4b). Additionally, magnetic resonance imaging (MRI) of the liver showed a low signal intensity on T1-weighted images, along with a high signal intensity on T2-weighted images, over the caudate lobe (Fig. 4c, d). The liver MRI in the formal report indicated the new lesion at the liver over S1 as being due to postradiation liver inflammation change rather than liver metastasis from esophageal cancer. Excluding the possibility of distant metastasis, a thoracoscopic esophagectomy with cervical esophagogastrostomy via the retrosternal route, along with a feeding jejunostomy, was performed 


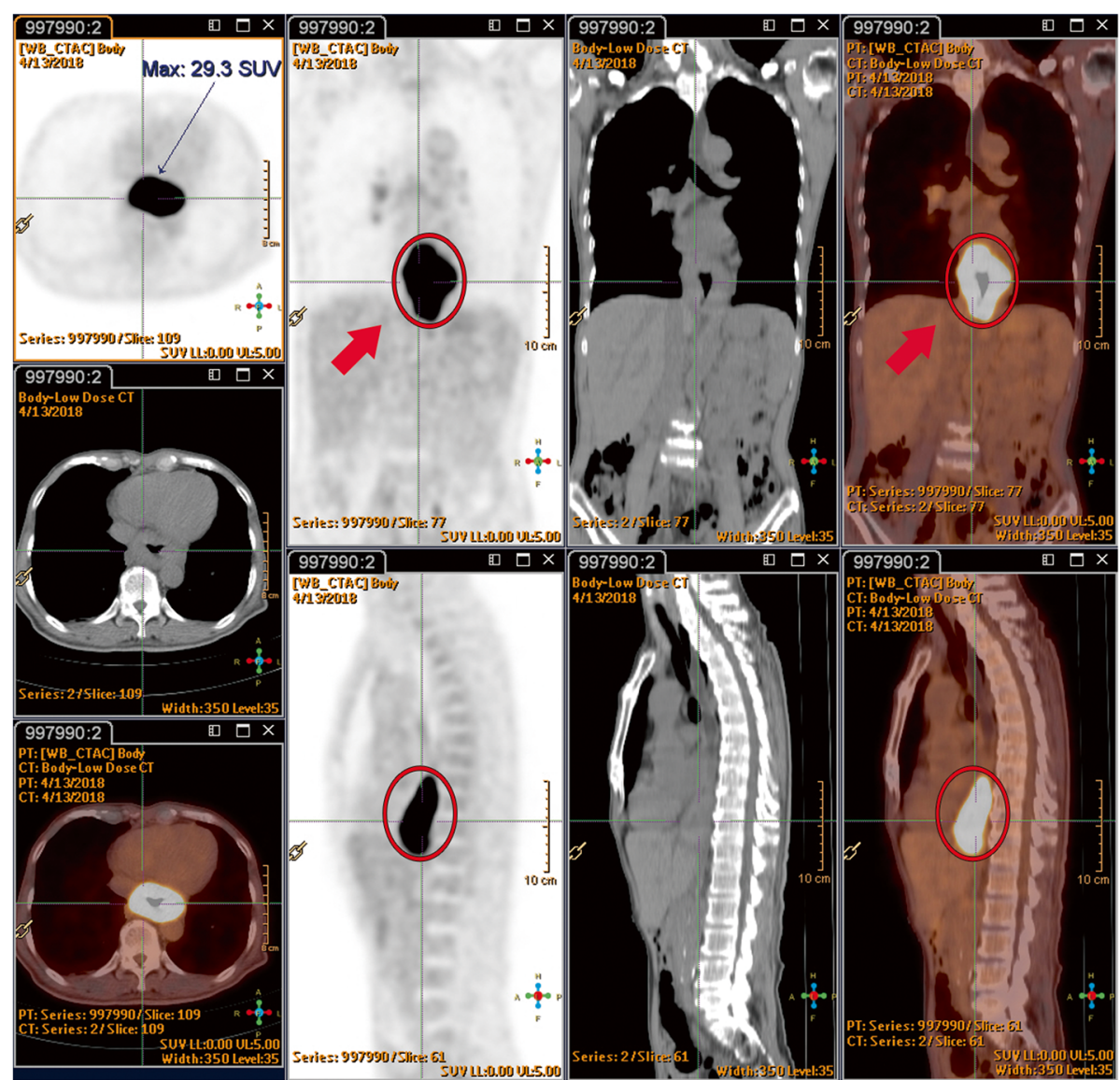

Fig. 1 Prior to neoadjuvant chemoradiotherapy, the esophageal tumor shows high ${ }^{18} \mathrm{~F}$-fluorodeoxyglucose uptake $(9.7 \times 5.6 \mathrm{~cm}$, maximum standardized uptake value 29.3/1 hour) (red circles). Prior to neoadjuvant chemoradiotherapy, there are no active lesions seen in liver segment I (red arrows)

smoothly 2 weeks later. A liver biopsy for both frozen section and pathology was also conducted during the surgery. The pathology report revealed esophageal cancer, specifically poorly differentiated squamous cell carcinoma, pT3N1M0. A valuable photograph was taken during surgery that revealed inflammation of the caudate lobe. The photograph also showed a manifested dark red color due to liver congestion containing a soft, smooth surface without adherence to the surrounding tissue (Fig. 5a, b), with no palpable hard nodules being seen in the lesion. There was no obvious tumor metastasis or enlarged lymph node discovered in the abdomen during the operation. The histology elucidated sinusoidal congestion with attenuated hepatic cords, which were filled with erythrocytes. However, there was no evidence of liver metastasis (Fig. 5c, d). The patient recovered uneventfully and was discharged with his oral intake performing smoothly, and a stable condition was observed during 12 months of outpatient department follow-up.

\section{Discussion}

The hepatic parenchyma is radiosensitive and has traditionally limited the use of RT in treating liver tumors or other perihepatic tumors located in the upper abdomen [9]. Preoperative whole-body PET-CT is frequently used to evaluate RT response and exclude metastases. Radiation-induced liver injury (RILI) may be detected by PET-CT within 2 to 6 weeks after completion of RT as being a focal area of increased FDG uptake (>50\% over baseline) in the liver adjacent to the irradiated field with an associated decreased attenuation seen by CT [5]. Common sites of metastatic spread in esophageal cancer include the abdominal lymph nodes, liver, and lungs [10]. In one study, it was revealed that up to $35 \%$ of patients with esophageal cancer will develop liver metastases [11]. In addition to metastatic disease, the liver is also particularly prone to radiation-induced liver disease (RILD) during RT for distal esophageal cancer, owing to its close proximity to the left lobe, which is accordingly included in the standard radiation field [11]. 


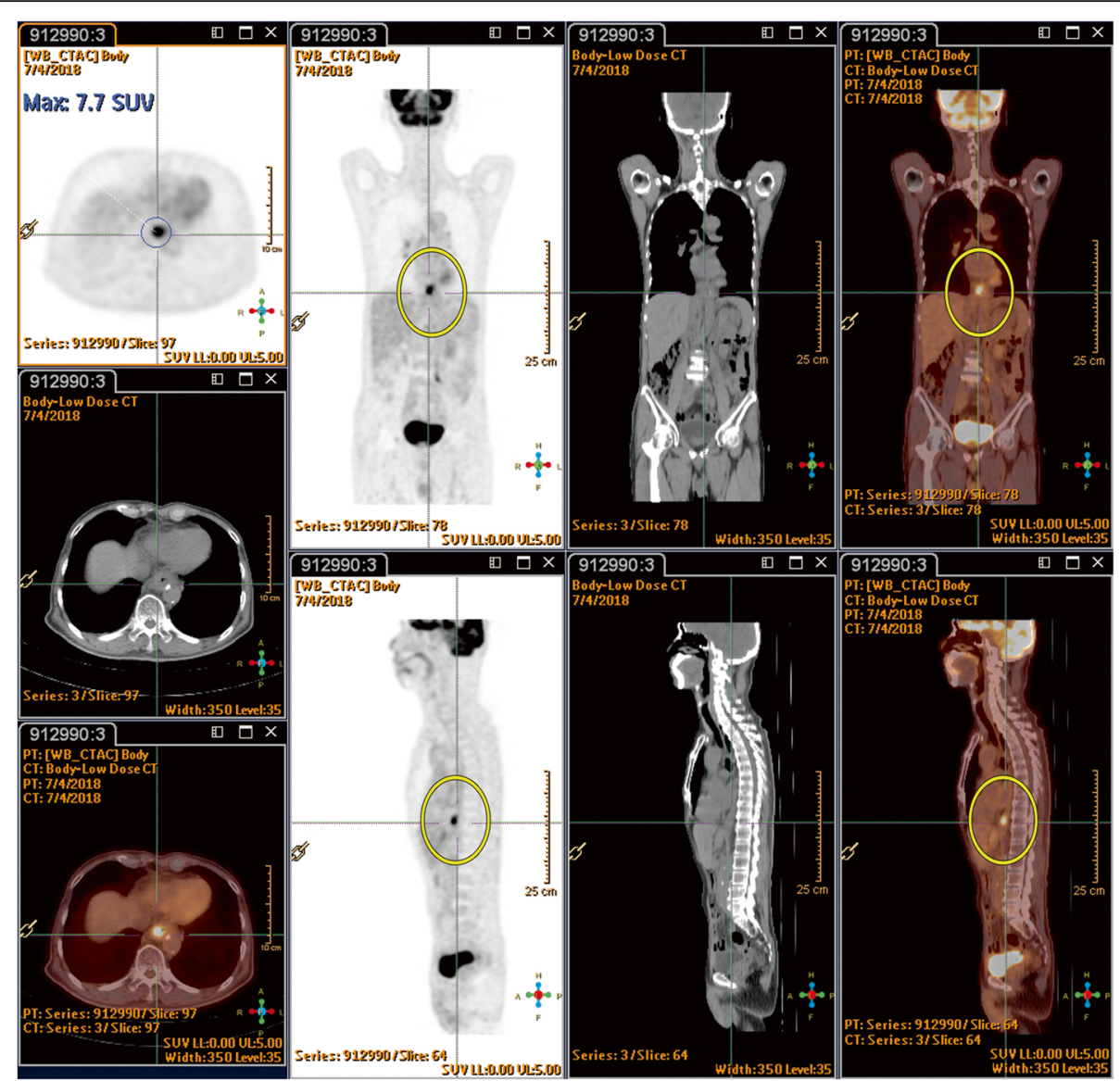

Fig. 2 Six weeks after neoadjuvant chemoradiotherapy, the esophageal tumor had regressed $(2.1 \times 1.6 \mathrm{~cm}$, maximum standardized uptake value $7.7 / 1$ hour; indicated by yellow circles)

When a patient displays FDG activity in the left or caudate liver lobes after CRT, a more detailed investigation should be performed in order to confirm or exclude distant metastases [12]. Our patient displayed no signs of tumor metastasis prior to neoadjuvant CRT. However, a new FDG uptake lesion was discovered during PETCT tumor restaging. Theoretically, the liver lesion may have been due to the chemotherapy, RT, or a synergic effect $[4,6,13]$. In patients with esophageal cancer undergoing neoadjuvant therapy, three-dimensional conformal therapy or intensity-modulated RT is employed in order to increase the radiation dose to the primary tumor while limiting damage to the surrounding healthy tissue [14]. However, given that the anatomical location of the lateral segment of the left lobe of the liver is adjacent to the distal esophagus, radiation injury to the liver is difficult to avoid [5]. There is an additional risk of RILD due to the concurrent administration of hepatotoxic chemotherapy to radiation, as well as irradiating a patient who has already received hepatotoxic chemotherapy prior to radiation [15]. However, cisplatin rarely results in hepatic toxicity (steatosis and cholestasis) when prescribed in standard doses [16]. Cisplatin induced hepatitis often elevates both aspartate transaminase (AST) and alanine transaminase (ALT) levels; however in our patient, the AST and ALT levels both before and after neoadjuvant CRT were within the normal range. Cisplatin-induced peliosis hepatis should affect the diffused liver rather than focusing on the caudate lobe due to the RT. With regard to a possible synergetic effect between cisplatin treatment and RT, additional research is still required. Radiation tolerance of the liver is less in patients with a deranged liver function [15]. These patients are more susceptible to the development of RILD [15].

Reed and Cox were the first to describe the pathophysiology of RILD and suggested that retrograde congestion was the main culprit [17]. Although RILD typically occurs 4-8 weeks after the termination of RT, it has been reported to appear as early as 2 weeks or as late as 7 months after RT [15]. In the available literature, RILI is described in about $8 \%$ of patients at the time of restaging. The precise mechanisms of RILD development remain largely unknown [18]. Although knowledge of 


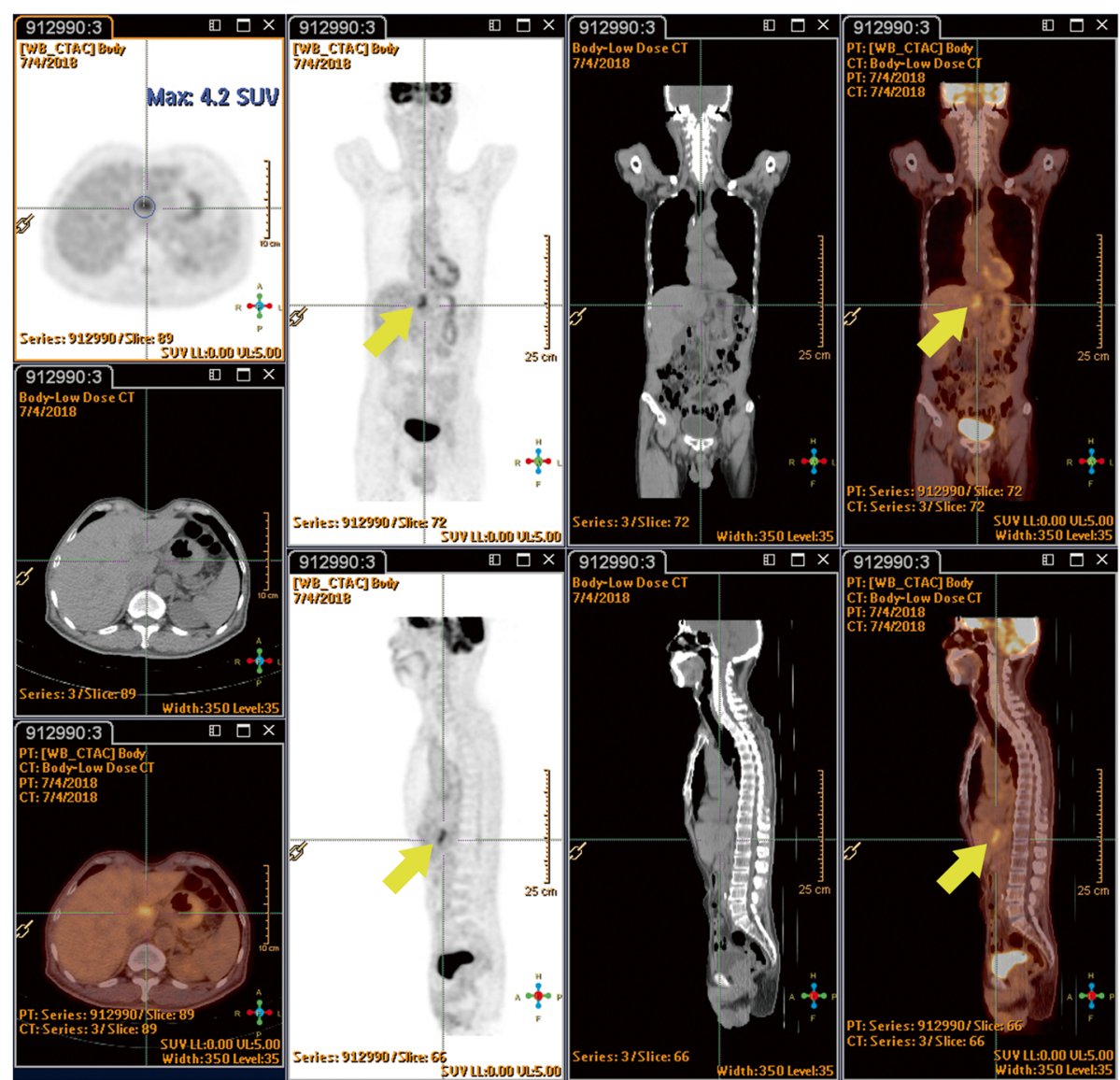

Fig. 3 Six weeks after neoadjuvant chemoradiotherapy, a new ${ }^{18} \mathrm{~F}$-fluorodeoxyglucose-avid lesion at liver segment I $(3.5 \times 1.5 \mathrm{~cm}$, maximum standardized uptake value 4.2/1 hour; indicated by yellow arrows)

RILD pathogenesis has improved in recent years, the molecular pathogenic mechanisms of RILD remain unclear [18]. RILD pathogenesis includes complex and multicellular responses associated with vascular changes, increased collagen synthesis, and sequential activation of key growth factors and cytokines, such as tumor necrosis factor- $\alpha$, transforming growth factor- $\beta$, and Hedgehog, which are important regulators in repair responses to liver damage [19]. Radiation injury to the liver most likely begins with damage to the endothelial cells of the central veins and sinusoids, which leads to sinusoidal congestion. In its more advanced stages, veno-occlusive disease is seen, resulting in backflow congestion and liver necrosis [20, 21].

There are two types of RILD: classic RILD and nonclassic RILD [18]. Patients experiencing classic RILD usually exhibit symptoms of fatigue, abdominal pain, increased abdominal girth, hepatomegaly, and anicteric ascites 1-3 months after liver RT [22]. The pathological hallmark of classic RILD is hepatic veno-occlusive disease, which is characterized by the complete obliteration of the central vein lumina by erythrocytes trapped in a network of reticulin and collagen fibers [17, 23]. Patients who develop nonclassic RILD have underlying chronic hepatic diseases, such as cirrhosis and viral hepatitis, and display more dysregulated hepatic functions with jaundice and/or remarkably elevated serum transaminases [18]. For example, patients with the hepatitis B virus are reportedly more vulnerable than noncarrier groups to developing RILD [24].

A similar report by DeLappe et al. described a 61year-old man with esophageal cancer who experienced a new increase in FDG uptake over the left lobe of the liver after undergoing 50.4-Gy RT, with the patient's CT-guided liver biopsy revealing no liver metastasis [25]. In Oregon, USA, 112 patients diagnosed with distal esophageal cancer were treated with neoadjuvant CRT, with 10 of them detected as having increased FDG uptake during PET-CT tumor restaging; however, 1 patient was later diagnosed with interval metastasis, and the others experienced RILI with an abnormal FDG uptake in the left caudate lobe from the liver [13]. Additionally, 26 patients were treated with neoadjuvant CRT for esophageal cancer in the MD Anderson Cancer Center, 


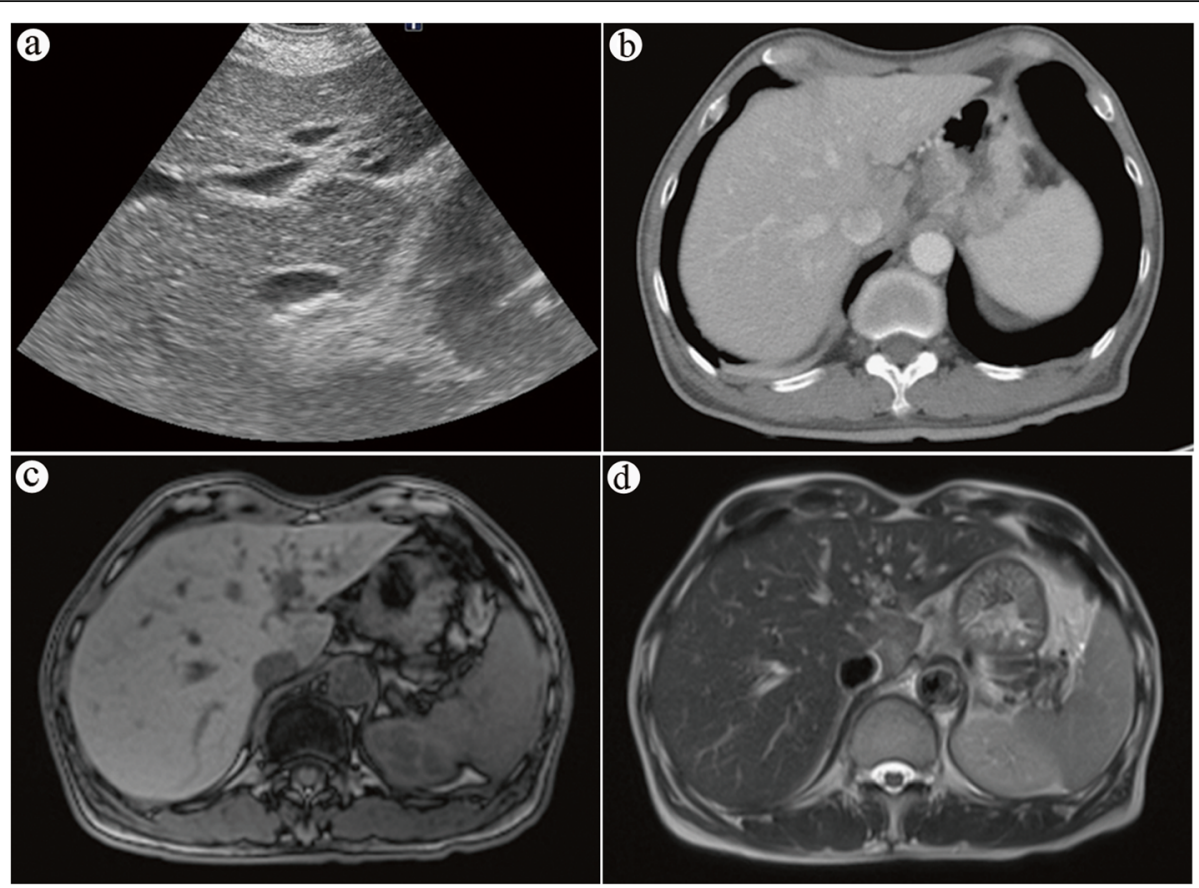

Fig. 4 a Sonography of the liver shows hypoechoic appearance over caudate lobe. b Contrast-enhanced computed tomography shows focally less enhancement in S1 of the liver. c Magnetic resonance imaging (MRI) of the liver shows a low signal intensity over the caudate lobe in T1weighted images. $\mathbf{d}$ MRI of the liver shows a high signal intensity over the caudate lobe in T2-weighted images
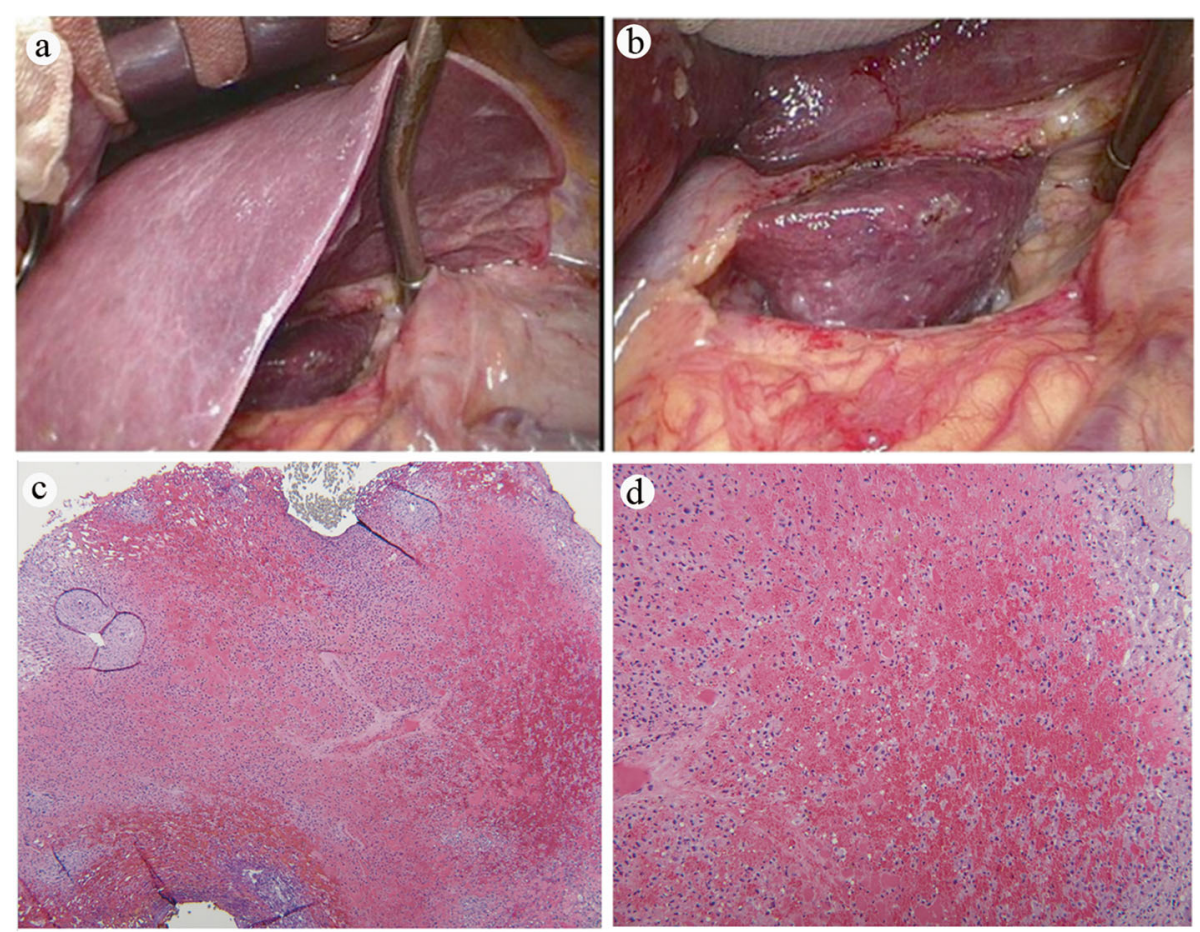

Fig. 5 a The normal liver compared with the inflammatory caudate lobe. b Up-close view of the liver with dark red, soft, bloody infiltration over the caudate lobe. Pathology of the liver caudate lobe. $\mathbf{c}$ Low-power field shows no evidence of tumor metastasis. Original magnification $\times 20$. $\mathbf{d}$ High-power field indicates congestion with attenuated hepatic cords and filled with erythrocytes. Original magnification $\times 40$ 
where 2 of them experienced an increased FDG uptake in the left lobe of the liver, whereas no FDG uptake occurred at the right lobe of the liver [5]. In a study by Francine et al. involving 205 patients who were undergoing neoadjuvant chemoradiation therapy, 6 of the patients showed an increased FDG uptake in the caudate or left liver lobe as seen on a PET-CT scan. None of the patients had any detected liver metastasis, as proved by biopsy, additional images, or continuous follow-up [12].

Characterizing RILD through noninvasive imaging has been challenging, and the techniques are still evolving [26]. CT findings within the irradiated portion of the liver after conventionally fractionated RT consist of a reversible, generally well-demarcated region of reduced enhancement when compared with the corresponding liver, possibly representing an increased water or fat content in the irradiated liver [27-29]. Increased enhancement can also be seen in the irradiated liver when compared with the adjacent normal liver because of an increased arterial flow or a delayed contrast clearance from radiation-induced veno-occlusive disease [30]. RILD may present itself as demarcated areas of hypo- or hyperattenuation in a nonanatomic distribution [31]. The appearance of radiation injury on CT scans is quite characteristic and generally shows sharp, straight margins that correspond to the portals used [5]. Metastatic lesions, on the other hand, are generally more masslike and rounded in contour on CT scans [5]. Magnetic resonance imaging shows changes after liver irradiation [26]. Decreased signal intensity on T1-weighted images, increased signal intensity on T2-weighted images, and an increased signal intensity on proton spectroscopic imaging of irradiated liver lobes suggests that the irradiated liver has increased water content [28]. MRI produces high-resolution images with good soft tissue contrast, which is ideal for distinguishing organs from surrounding tissue [32]. Various clinical studies have investigated the use of MRI to detect and monitor radiation-induced damage to the liver [33], myocardium $[34,35]$, and bone marrow [36, 37]. New foci of hepatic FDG avidity that develops during neoadjuvant chemoradiation of esophageal cancer are usually due to RILD. Increased FDG avidity in RILD results from inflammation caused by radiation, with an increased FDG uptake by active leukocytes [25]. This reflects the low likelihood of metastases developing during neoadjuvant CRT [13]. The location of the new foci of FDG avidity may be important. All the foci due to RILD developed in the left and caudate lobes, within the presumed radiation field [13]. The involved organ will be related to chemoradiation-induced injuries, though the exact frequency with consensus is not made clear in the literature, but vulnerable organs include the lung, liver, heart, spinal cord, kidney, and bowel, as well as others. The dose of radiation causing RILD has ranged from a pure dose to $70 \mathrm{cGy}$, combining chemotherapy with $30 \mathrm{cGy}$, or in underlying liver disease with a de-escalating dose. Currently, no special report is available to compare the maximum standardized uptake value (SUVmax) in PET$\mathrm{CT}$ between radiation injury and metastatic lesions, but some studies have revealed an SUVmax of RILD range at about 4-9/hour, but metastatic lesions can sometimes be higher than 10/hour; if SUVmax is more than 10/ hour, it must be due to metastasis.

\section{Conclusions}

New foci from increased FDG avidity are commonly seen in the caudate and left hepatic lobes of the liver during neoadjuvant chemoradiation of distal esophageal cancer, and these findings can be RILD rather than metastatic disease [13]. Awareness of the pitfalls of a high FDG uptake in RILI is crucial in order to avoid misinterpretation and overstaging. Except for the location of FDG uptake, the shape of the lesion, and a SUVmax value ( $>10 /$ hour), a convincing liver MRI or even a liver biopsy can provide accurate information to help distinguish RILI from liver metastasis.

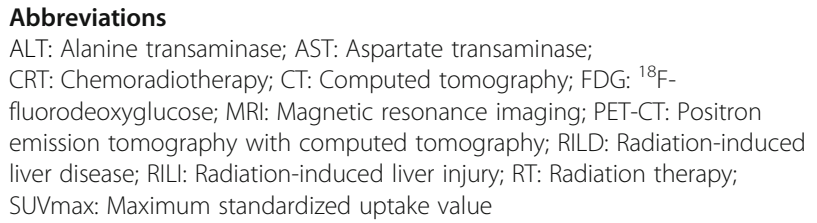

Authors' contributions

SES was a major contributor to the writing of the manuscript. YHL, YWH, YLL, and HWT analyzed and interpreted the patient data. SCH was involved in manuscript writing, review, and editing. All authors read and approved the final manuscript.

\section{Funding}

Not applicable.

\section{Availability of data and materials}

Data sharing is not applicable to this article, because no datasets were generated or analyzed during the current study.

Ethics approval and consent to participate

Not applicable.

\section{Consent for publication}

Written informed consent was obtained from the patient for publication of this case report and any accompanying images. A copy of the written consent is available for review from the Editor-in-Chief of this journal.

\section{Competing interests}

The authors declare that they have no competing interests.

\section{Author details}

'Division of Thoracic Surgery, Taichung Veterans General Hospital, 1650Taiwan Boulevard Sect. 4, Taichung, Taiwan. ${ }^{2}$ Institute of Clinical Medicine, National Yang-Ming University, Taipei, Taiwan. ${ }^{3}$ Department of Pathology, Veterans General Hospital, 1650Taiwan Boulevard Sect. 4, 
Taichung, Taiwan. ${ }^{4}$ National Chi Nan University, Nantou, Taiwan. ${ }^{5}$ Institute of New Drug Development, China Medical University, Taichung Joint PI, IBMS, Academia Sinica 7F, No. 6, Xueshi Road, North District, Taichung City 404, Taiwan. 'Integrative Stem Cell Center, China Medical University Hospital, Taichung Joint PI, IBMS, Academia Sinica 7F, No. 6, Xueshi Road, North District, Taichung City 404, Taiwan.

Received: 23 February 2020 Accepted: 28 April 2020

Published online: 07 July 2020

\section{References}

1. Zhang M, Wu AJ. Radiation techniques for esophageal cancer. Chin Clin Oncol. 2017;6(5):45.

2. Bosset JF, Gignoux M, Triboulet JP, et al. Chemoradiotherapy followed by surgery compared with surgery alone in squamous cell cancer of the esophagus. N Engl J Med. 1997;337:161-7.

3. Heeren PA, Jager PL, Bongaerts F, et al. Detection of distant metastases in esophageal cancer with ${ }^{18}$ F-FDG PET. J Nucl Med. 2004;45(6):980-7.

4. Bruzzi JF, Munden RF, Truong MT, et al. PET/CT of esophageal cancer: its role in clinical management. Radiographics. 2007;27(6):1635-52.

5. lyer RB, Balachandran A, Bruzzi JF, et al. PET/CT and hepatic radiation injury in esophageal cancer patients. Cancer Imaging. 2007;7:189-94.

6. Stiekema J, Vermeulen $D$, Vegt $E$, et al. Detecting interval metastases and response assessment using ${ }^{18} \mathrm{~F}$-FDG PET/CT after neoadjuvant chemoradiotherapy for esophageal cancer. Clin Nucl Med. 2014;39(10): 862-7.

7. Nijkamp J, Rossi M, Lebesque J, et al. Relating acute esophagitis to radiotherapy dose using FDG-PET in concurrent chemo-radiotherapy for locally advanced non-small cell lung cancer. Radiother Oncol. 2013;106(1): 118-23.

8. Ulaner GA, Lyall A. Identifying and distinguishing treatment effects and complications from malignancy at FDG PET/CT. Radiographics. 2013;33(6): 1817-34.

9. Rabe TM, Yokoo T, Meyer J, et al. Radiation-induced liver injury mimicking metastatic disease in a patient with esophageal cancer: correlation of positron emission tomography/computed tomography with magnetic resonance imaging and literature review. J Comput Assist Tomogr. 2016; 40(4):560-3.

10. Daly JM, Fry WA, Little AG, et al. Esophageal cancer: results of an American College of Surgeons patient care evaluation study. J Am Coll Surg. 2000;190: 562-72.

11. Nakahara T, Takagi Y, Takemasa K, et al. Dose-related fluorodeoxyglucose uptake in acute radiation-induced hepatitis. Eur J Gastroenterol Hepatol. 2008:20:1040-4.

12. Voncken FEM, Aleman BMP, van Dieren JM, et al. Radiation-induced liver injury mimicking liver metastases on FDG-PET-CT after chemoradiotherapy for esophageal cancer: a retrospective study and literature review. Strahlenther Onkol. 2018;194(2):156-63.

13. Grant MJ, Didier RA, Stevens JS, et al. Radiation-induced liver disease as a mimic of liver metastases at serial PET/CT during neoadjuvant chemoradiation of distal esophageal cancer. Abdom Imaging. 2014;39(5): 963-8.

14. Wieder HA, Brucher BL, Zimmermann F, et al. Time course of tumor metabolic activity during chemoradiotherapy of esophageal squamous cell carcinoma and response to treatment. J Clin Oncol. 2004;22:900-8.

15. Benson R, Madan R, Kilambi R, Chander S. Radiation induced liver disease: a clinical update. J Egypt Natl Canc Inst. 2016;28(1):7-11.

16. King PD, Perry MC. Hepatotoxicity of chemotherapy. Oncologist. 2001;6(2): $162-76$

17. Reed GB Jr, Cox AJ Jr. The human liver after radiation injury: a form of venoocclusive disease. Am J Pathol. 1996:48:597-611.

18. Kim J, Jung Y. Radiation-induced liver disease: current understanding and future perspectives. Exp Mol Med. 2017;49(7):e359.

19. Lee UE, Friedman SL. Mechanisms of hepatic fibrogenesis. Best Pract Res Clin Gastroenterol. 2011;25:195-206.

20. Pan CC, Kavanagh BD, Dawson LA, et al. Radiation-associated liver injury. Int J Radiat Oncol Biol Phys. 2010;76(Suppl 3):S94-100.

21. Sempoux C, Horsmans Y, Geubel A, et al. Severe radiation-induced liver disease following localized radiation therapy for biliopancreatic carcinoma: activation of hepatic stellate cells as an early event. Hepatology. 1997;26(1): 128-34.
22. Lawrence TS, Robertson JM, Anscher MS, et al. Hepatic toxicity resulting from cancer treatment. Int J Radiat Oncol Biol Phys. 1995;31:1237-48.

23. Ogata K, Hizawa K, Yoshida M, et al. Hepatic injury following irradiation - a morphologic study. Tokushima J Exp Med. 1963;10:240-51.

24. Chou CH, Chen PJ, Lee PH, et al. Radiation induced hepatitis B virus reactivation in liver mediated by the bystander effect from irradiated endothelial cells. Clin Cancer Res. 2007;13:851-7.

25. DeLappe EM, Truong MT, et al. Hepatic radiation injury mimicking a metastasis on positron-emission tomography/computed tomography in a patient with esophageal carcinoma: a case report. J Thorac Oncol. 2009; 37(7):709-11.

26. Guha C, Kavanagh BD. Hepatic radiation toxicity: avoidance and amelioration. Semin Radiat Oncol. 2011;21(4):256-63.

27. Jeffrey RB Jr, Moss AA, Quivey JM, et al. CT of radiation-induced hepatic injury. AJR Am J Roentgenol. 1980;135:445-8.

28. Unger EC, Lee JK, Weyman PJ, et al. CT and MR imaging of radiation hepatitis. J Comput Assist Tomogr. 1987;11:264-8.

29. Yamasaki SA, Marn CS, Francis IR, et al. High-dose localized radiation therapy for treatment of hepatic malignant tumors: $C T$ findings and their relation to radiation hepatitis. AJR Am J Roentgenol. 1995;165:79-84.

30. Kwek J, lyer $R$, Dunnington J, et al. Spectrum of imaging findings in the abdomen after radiotherapy. AJR Am J Roentgenol. 2006;187:1204-11.

31. Itai Y, Murata S, Kurosaki Y. Straight border sign of the liver: spectrum of CT appearances and causes. Radiographics. 1995;15:1089-102.

32. Jelvehgaran P, Steinberg JD, Khmelinskii A, et al. Evaluation of acute esophageal radiation-induced damage using magnetic resonance imaging: a feasibility study in mice. Radiat Oncol. 2019;14(1):188.

33. Seidensticker M, Burak M, Kalinski T, et al. Radiation-induced liver damage: correlation of histopathology with hepatobiliary magnetic resonance imaging, a feasibility study. Cardiovasc Intervent Radiol. 2015;38(1):213-21.

34. Umezawa R, Ota H, Takanami K, et al. MRI findings of radiation-induced myocardial damage in patients with oesophageal cancer. Clin Radiol. 2014; 69(12):1273-9

35. MacHann W, Beer M, Breunig M, et al. Cardiac magnetic resonance imaging findings in 20-year survivors of mediastinal radiotherapy for Hodgkin's disease. Int J Radiat Oncol Biol Phys. 2011;79(4):1117-23.

36. Yankelevitz DF, Henschke Cl, Knapp PH, et al. Effect of radiation therapy on thoracic and lumbar bone marrow: Evaluation with MR imaging. AJR Am J Roentgenol. 1991;157(1):87-92.

37. Daldrup-Link HE, Henning T, Link TM. MR imaging of therapy-induced changes of bone marrow. Eur Radiol. 2007;17(3):743-61.

\section{Publisher's Note}

Springer Nature remains neutral with regard to jurisdictional claims in published maps and institutional affiliations.

Ready to submit your research? Choose BMC and benefit from:

- fast, convenient online submission

- thorough peer review by experienced researchers in your field

- rapid publication on acceptance

- support for research data, including large and complex data types

- gold Open Access which fosters wider collaboration and increased citations

- maximum visibility for your research: over $100 \mathrm{M}$ website views per year

At BMC, research is always in progress.

Learn more biomedcentral.com/submissions 